\title{
The Role of Organizational Leadership to Enhance Top 10 CSR Issues and Trends in The Global Economy
}

\author{
Dewi Rachmayanti, Musa Hubeis, M. Syamsul Maarif, M. Joko Affandi \\ Bogor Agricultural University (IPB). Jl. Raya Darmaga Kampus IPB Darmaga, Bogor 16680 \\ West Java, Indonesia
}

\section{ART ICLE INF O \\ Keywords: \\ CRS issues and trends, organizational leadership, the global econom, \\ Indonesia mining sector}

A B S T R A C T

Research on leadership and its relationship with organizational performance have been carried out and not considered Corporate Social Responsibility (CSR) performance, especially in the field of community development (Comdev) and even done partially. This study aims to investigate the role of organizational leadership to enhance Top 10 CSR issues and trends in the global economy which defines roles and leadership competencies. Thirteen experts were involved in the Forum of Multi Stakeholder Corporate Social Responsibility (MSHCSR) through Focus Group Discussion (FGD). Data by cluster random sampling were statistically analyzed with Assumption Surfacing and Testing Strategy (SAST). The results showed from FGD experts stating if eight roles and eight competencies of the organization's leadership is very important and influential to enhance Top 10 CSR issues and trends in the global economy.

(C) 2014 IRJBS, All rights reserved.

Corresponding author:

dheve@yahoo.com

\section{INTRODUCTION}

The globalization of economic, political and social environments converge with technological advances and speed of access on information across nations really give effect to business world. As we read in the Indonesian Economic Outlook 2008-2012, January 2008 edition, Indonesian economy was quite high and accounted for in the global economy. In terms of the global economy, the Corporate Social Responsibility (CSR) as a form of corporate responsibility towards stakeholders is considered to be an economic agent (Bird et al., 2007; Fiori et al. 2007) following a surge in attention towards firms and relationship with stakeholders.

CSR generally refers to business principles in a variety of managerial decision making, emphasizing the obligation and accountability 
to the community (Bird et al., 2007; Carroll and Bucholtz 2003). CSR is a company's commitment to carry out its operations to at all times provides a positive contribution to the social community and the environment.

Along with the company's operations that give different impacts, some laws and regulations also govern the relationship between the company and its environment. Law No. 22 of 2001 on Oil and Gas (Law No. 22/2001) that business entities or permanent establishments that carry out business activities of Oil and Gas co-responsibility for developing the environment and local communities. High-profile companies generally gained big public attention as a result of operational activities which are potential to intersect with broader interests. Such companies are those having leading stocks, or stocks of the most desirable (blue chip), and belong to the ranks of the stock position $\mathrm{Li}$ quates ( $L Q)-45$ established by the Indonesia Stock Exchange (IDX). Mining companies are included in the leading stocks LQ-45 and therefore get more attention from the communities and sometimes accusation that its operations have caused environmental damage. Mechanization of mining equipment and processing technology development have made lower quality mineral extraction more economical and caused the scale of mining expanded. Several companies have expressed their contribution in social responsibility in a transparent manner. Considering the expansive scale and scope of corporate social responsibility, there is a need for transparancy of the respective companies, especially mining companies to express their contribution in dollars and dollars into annual reports.

Government pressure on the implementation of CSR continues to be coupled with a variety of issues and trends of CSR in today's global economy. Call it the Business for Social Responsibility (BSR), which for 20 years has accompanied companies in various industries around the world in an effort to increase awareness of the importance of the role of the company in the implementation of social responsibility in order to continue to protect the environment and rare natural resources by focusing on the sustainable economic development either for stakeholders and companies primarily those in mining and energy sectors (Davis, \& Oxman, 2013).

There are ten CSR issues and trends that become the demand of the global economy. The local license is a strong community participation of the company which is based on trust and partnerships with local communities and their involvement in the projects of scheduled business strategy. This is the key of long-term company success. The integration of CSR into a major business is a full integration of CSR into business strategy, function, and operation by local national companies. Cross-functional coordination in the response to the environmental impact, legal issues, procurement, human resources, government relations, and community. Collaborative approach is a partnership with the local government and the various elements of society in controlling air quality and carbon emissions, climate adaptation, the use of water and land, and local employment for the sake of long-term success of the company. It is also important for companies to consider human rights issues not only to reduce the risk, but also to increase social investment programming and simultaneously provide local benefits that help companies keep and maintain licenses. Local content and the demands of profit sharing are other important issues. The government legalize through legislation and regulations the importance of local content in each of the company's business processes. Supply chain are practices that promote and facilitate 'local content' as a goal in the supply chain. This is critical for the company to pay attention. Non Governmental Organisations (NGOs) agendas are also important to consider by the companys. They need to reconsider their relationship with $\mathrm{NGOs}$ and seek constructive ways to find common ground in response to current issues, transparency of management and 
various issues related to social responsibility and human rights. Competition in water resources is an innovative solution for sustainable water management and company investment on this is absolutely needed. In labor relations, there is a need to review the management practices on issues like labor, the workers of contractors and business partners in order to avoid tensions and violent confrontations during ongoing business processes. Establishing cooperation with labour unions and local partners is an important issue for the company at this time. In order to improve the accountability, the government, companies and NGOs agree that better transparency is needed in the provision of essential services to the community such as fresh water, health care, and education (Davis \& Oxman, 2013)

CSR and social performance may not be identical to the ethical and moral leadership however a strong relationship between the social performance and ethical-moral leadership has been widely recognized. Swanson (1995) stated corporate social responsibility should highlight the moral obligation that its operation is community-oriented business. Goleman et al., (2004) stated that a leader is able to generate commitment, motivation and optimism in carrying out the work and foster an atmosphere of cooperation, a passion that can affect the behavior of subordinates based on the values that are held to achieve organizational goals. Finkelstein and Hambrick (1996) argues that the Managing Director has the authority and power of decision-making of the company as part of a form of responsibility in the company's activities, including corporate social responsibility activities.

Based on the recent phenomenon, the development of business and more commanding government regulation on the implementation of CSR and environmental policies and on the other hand there are still many erroneous cases and irregularities in the field such as damage to the environment (water, soil, and noise), conflict with the community demanding a more comprehensive
CSR implementation and integration, as well as the demands of the roles and competencies of leadership in CSR program achievements, it was then conducted a research with the title: The Role of Organizational Leadership to Enhance Top 10 CSR Issues and Trends in the Global Economy.

\section{Hypothesis Development}

The government laws regulating the existence and obligation of companies to maintain the environment balance should become an important part in the company's goals. This may be reflected by brainstorming to have their own programs and policies on CSR, especially the community development. When noticing all changing community values regarding environment preservation the business pratitioners should be incited to compete in developing the company's CSR activities.

This study aims at:

1 Formulating the priority of strategic company decisions and recommendations from the Ten CSR Issues and Trends in the global economy.

2 Assessing the role and competencies of leadership toward the social responsibility performance of companies in the mining sector.

\section{Organizational Leadership}

Leadership was variously defined but in general leadership describes the relationship between the leader (leader) with the follower. (Locander et al. 2002) explains that leadership implies leaders influencing followers but the relationship between the leaders and the followers is mutually beneficial to both parties. Lok and Crawford (2001) sees leadership as a process of influencing the activities of an organization in an effort to set and achieve goals.

\section{Leadership Theory}

Contingency Theory is leadership approach that encourages leaders understand their own 
behavior. This theory says that leadership effectiveness is a function of various aspects of leadership situation (Ivancevich, Konopaske, Matteson, 2011) includes: Fiedler contingency model (Fiedler's Contingency Model). This model maintains that group performance depends on an appropriate match between the leader's style and the situation and level of control and influence given to the leader. Fiedler creates the instrument, which he called Least Preffered Co-Worker (LPC), which measures whether a leader is task-oriented or relations-oriented. Furthermore, Fiedler (1967) defines the factors of leader and member relations, task structure and position power as the main situational factors that determine the leadership effectiveness.

The transformational leader is the one who raised the needs of followers in line with the goals and objectives of the leaders themselves. Transformational leader has been characterized as a person that can articulate a positive vision of the future that can be shared with subordinates and among peers, giving attention to the diversity and intellectually stimulating subordinates to do things beyond what was thought possible for him (Yammarino \& Bass 1990).

Trasnformational leaders interact with subordinates in ways that can be seen by subordinates as intellectually challenging, inspirational, sensitive and supportif and express a mission which is representative of the collective view classified as transformational. Studies showed that such leaders were seen in very positive terms both by subordinates and superiors. It is often associated with groups and organizations that are very productive (Hater \& Bass 1988). Transformational leader raises the need of followers to a smiliar level of his and promotes the dramatic changes of individuals, groups and organizations. Transformational leaders lead changes and try to change the orientation of subordinates towards the work of his own desires towards real commitment. Transformational leaders develop the followers (through the efforts of coaching and personal involvement) to the point where the follower is able to take on leadership roles and to perform beyond the established standards or goals (Bass 1990, 1993, and Avolio and Bass 1995).

According to Bass (1985) there are four key dimensions of leadership to be actioned in order to achieve the transformation of subordinates, peers, and organizations, namely attributed charisma or idealized influence, inspirational motivation, individualized consideration, and intellectual stimulation. Bass (1985) stated charisma as the center of the process of transformational leadership and is considered a key component of transformational leadership (Bass, 1985, and 1990; Yukl 1989). These involve in gaining the trust, respect and confidence of other people to take a stand on difficult situations, showing confidence, emphasizing the importance of purpose, commitment, values and represents the ethical consequences of decisions. Idealized influence behavior captures behavioral-based charismatic leadership and charisma captures non-behavioralbased charismatic leadership (Avolio \& Bass 1995). Inspirational motivation relates with the ability to communicate the vision with fluency and confidence in a positive way and increase optimism and enthusiasm for the tasks ahead. Some researchers have suggested that the ability of the leader to define, articulate and communicate the mission is as important as the nature of vision (Behling \& McFillen 1996). The purpose of inspirational motivation is to inspire his followers with morals and ethics as well as carrying values embedded in the vision that the leaders want followers adopted as their own. While Bass (1997) defines inspirational motivation as the ability to articulate a vision for the future, challenging followers to high standards, talk optimistically with enthusiasm and provide encouragement and meaning upon the need to be resolved. This concept requires a high communication skill and ability to build trust and respect for the leader who is able to take actions based on morals and 
ethics. Individualized consideration means that transformational leaders relate with others as individuals and understand that every individual has different needs and abilities. Transformational leaders achieve this by listening attentively, recognize and appreciate the contribution of each individual, developing, teaching, advising and coaching. Bass and Avolio (1993) reported that individual consideration is required for the basic quality of effective transformational leadership. Part of the importance of this element is the ability of a leader to align goals and vision with those of individuals effectively in one to one interaction which in turn increases the likelihood of achieving better organizational outcomes (Zaleznik 1963). Intellectualstimulationmeans that transformational leaders know that creativity, knowledge, creation and continuous improvement are the only real way to compete with sustainable profit. This type of leader is constantly challenging old assumptions and ways of doing things, encouraging creativity, emphasizing the use of intelligence and stimulation of others, new perspectives and ways of doing things. Transformational leaders encourage the expression of new ideas and reasons from subordinates (Bass, 1997).

\section{The Role of Leadership and Competency in Community Development}

Community development is seen as a process, method, program, and movement (Sanders, 1958). As a process (Hope, 1980) it involves solving the social and economic problems of communities by seeking help from the government, nongovernmental and private organizations. Through this process, the community moves by stages from one condition or state to the next which involves a progression of changes (Sanders, 1958). On the other hand, community development is also a method which put the emphasis on both the process and the objectives to be achieved As a program, community development is stated as a set of procedures and the content is a set of activities to be accomplished by the community members. Finally as a movement, it is seen as a crusade or a course to which people become committed. Ploch (1976) defined community development as the active voluntary involvement of community residents in a process to improve community life.

In a study conducted by Mohammed and Silong (2008), on the role of leadership in community development in Malaysia there are eight roles of leader who is considered the most important of the survey and interview: leading a multi-racial team, change agent, problem-solver, negotiator or mediator, planning and conducting community programs, communicator, resource-linker and manager.

While in the study conducted by Clark and Gong (2011), some questions were passed on the participants of the MSDL (Mid-South Delta Leader) program, which was a leadership competency development program in the Mississippi Delta Region to improve community development. The questions were: networking/collaboration across state lines; understanding diversity/cultural differences; relationship building; understanding how leadership affects community change; better communication; new outlook/clearer vision for the future; All were working together towards the same goal namely understanding local and state roles and interactions in communities.

\section{Corporate Social Responsibility}

According to the World Business Council for Sustainable Development (WBCSD), CSR or corporate social responsibility is defined as a business commitment to contribute to sustainable economic development, in collaboration with employees and their representatives, their families, the local and broader communities to improve the quality of life in a useful way for their business and general development. Despite that CSR has been variously defined, all these definitions describe the common theme that (1) the business must consider the economic impact, social impact and environmental impact of its regular operations to 
stakeholders and the environment, and (2) CSR requires companies to minimize side effects and maximize the benefits consequential damages of any action against the stakeholders and the environment. (World Business Council for Sustainable Development 2000).

According to Branco and Rodrigues (2006), companies can benefit from CSR. Some notable internal benefits are; (1) reducing operational costs and increasing revenue from grants and incentives, (2) managerial competencies on social responsibility may lead to better management in general, (3) developing new resources and capabilities related to know-how and corporate culture, which may lead to efficiency, (4) CSR boosts firm's reputation, which may likely attract better job applicants, and (5) maintaining relatively high work satisfaction and happy workforce

Some prominent external benefits are (Bird et al., 2007; Branco and Rodrigues 2006; Fiori et al. 2007; www.simplycsr.co.uk, 2012; Uwuigbe, et al, 2011); (1) firm's reputation represents an intangible resource, (2) CSR investment triggers the creation or depletion of other fundamental intangible resources, which may differentiate one firm from another within the same industry, (3) good CSR prompts improved relationships with customers, investors, bankers, suppliers and competitors, (4) any disclosures on firm's behaviors and outcomes of social responsibilities may build a positive image, which may win new businesses, and (5) easier access to financial assistance, and funding opportunities.

\section{Roles of CSR}

The most common query encircle CSR is simply either firms are really trying to do the right thing in their routine business operations, or firms are just aiming for company image?

\section{CSR on Employment Relations}

There is a general understanding that the concept of CSR could serve as a bridge between issues of governance, covering the notions of equity and fairness in employment and in society (Fiori, et al, 2007; Liu and Fong, 2010; Neal, 2008). This expanded coverage of CSR differs both from a traditional conception of CSR, by referring to compliance with corporate behavioral standards (Neal, 2008). CSR should be perceived as mechanisms on managerial, regulatory and financial dimensions in firms.

Fiori et al. (2007) and Liu and Fong (2010) defined the dimensions of employment is based on five measures, which are; (1) health and safety systems, (2) systems for employee training and development, (3) equal opportunities policies, (4) systems for good employee relations, and (5) systems for job creation and security.

\section{CSR on Enviroment Performance}

CSR activities on the environment should be based on the philosophy of continuous improvement of environmental policies and development strategies to reduce adverse impacts on the environment (Pearce and Robinson, 2011; Spada, 2008), Lyon and Maxwell (2008), including Johnsen and Gjoelberg (2009) and Spada (2008) indicated that the attention toward environmental initiatives has increased drastically. The attention is basically coming from market for products, capital, and labor, as drivers of improvements.

In the market places, demand plays an important role. When the level of market demand for less environmentally friendly products increases, the general level of price of those products drop. At a lower price, public may decide to buy and/or consume more. Nonetheless, as indicated by Lyon and Maxwell (2008), as the less environmentally friendly products gain more bargaining power in the marketplaces, the general level of price may likely to increase. The relatively high price of the less environmentally friendly products may signal the relatively high quality (Handelman and Bello, 2004). This may be triggering public urge to increase purchases. 
In terms of the labor market, the workforce is also providing potential incentives on CSR initiatives. As people may want to work with good firms, which are also doing well, firms may have to align with such employees' environmental values (Bird, et al, 2007; Lyon and Maxwell, 2008; Margolis and Elfenbein, 2007). On the other side, the market supply side also holds crucial functioning terms of pushing firms toward eco-friendly products by ensuring efficient use of resources, and reducing wastes and pollution. Though cost reduction may not be present for the operational expenses, firms that produce both friendly and less-friendly products may also benefits with those imperfect product substitutes. When firms start adopting eco-friendly initiatives, production level on lessfriendly products may slide. This affects the general level of price. Market demand for lessfriendly products may also likely to fall while demand for eco-friendly products jumps. At the end, profitability for those products may both swell (Lyon and Maxwell, 2008).

Following what Fiori, et al (2007) had previously studied, those analyses on environmental CSR can be categorized in three dimensions: the quality of environmental policies, the environmental management systems, and environmental reporting.

\section{CSR on Community Development}

Community development signifies the indicator of community responsiveness. D'Amato, et al. (2009) on "Corporate Social Responsibility and Sustainable Business" explained that relationship between firms and society had increased expectations (World Business Council for Sustainable Development, 2000). With the new level of expectation, there were new rules, regulations, and tactics. The relational effectiveness between firms and society is due to community attachment. Non-local firms may be seen as strictly profit-oriented business establishments with no concerns on local issues (Handelman and Bello, 2004). Hence, those non- local firms may not be expected to comply with local issues.

Nonetheless, firms are expected to commit to the following (D'Amato, et al, 2009; Fiori, et al, 2007; Pearce and Robinson, 2011; Spada, 2008); (1) safeguard the environment, (2) support human rights, (3) eliminate child labor, (4) adopt codes of ethics, (5) enter into partnerships with NGOs, (6) display openness and transparency in relationships with customers, employees, community groups, and governmental organizations, (7) promote diversity in the workplace, (8) help communities solve their social problems, and (9) consult with community residents on business plans and strategies (D'Amato et al. 2009; Fiori et al. 2007; Pearce and Robinson 2011; Spada 2008)..

\section{METHODS}

\section{Research Design}

This study was conducted in one mining sector company included in the category of high-profile listed on the Indonesia Stock Exchange. To disclose Roles and organizational Leadership Competencies and 10 CSR Issues and Trends in 2013 qualitative methods is used through focus group discussion (FGD) conducted in August 2014 by the Multi Stakeholder Corporate Social Responsibility (MSHCSR). FGD involving 13 experts by cluster random sampling in the field of CSR which involves elements of the Company, Local East Kutai Government, Non Governmental Organizations, the National Committee of Indonesian Youth (KNPI) and educational institutions that have a major role in decisionmaking.

Through FGD in MSHCSR Forum for strategic assumptions rating, the scale of Semantic Differential (SD) was used to determine the perceptions of the respondents (experts) for the identification of 10 CSR Issues and Trends in the global economy in the seven categories of options. The statement is divided into two following rating assumptions. 
a. How important is the influence of the assumption of the clarity and accuracy of strategic CSR themes. $1=$ least important and $7=$ most important

b. How much confidence that these assumptions can be justified $1=$ most uncertain and $7=$ most certain

In order to explore and formulate leadership competencies, experts who are members of the Forum MSHCSR conducted a series of intensive discussions among the institutions to define core competencies that must be possessed by a leader in the effort to increase the Top ten CSR issues and trends in the global economy.

\section{RESULTS AND DISCUSSION}

Focus Group Discussion

SAST Management, CSR Ten (10) Issues and

Trends.

In models Strategy Assumption Surfacing and Testing (SAST) this whole primary data obtained by the FGD to thirteen (13) experts who are representatives of companies, governments, educational institutions, youth organizations and non-governmental organizations (NGOs). The thirteen (13) experts were actively involved in the discussion forum with duration of 1 or 3 hours. FGD held on Thursday, August 29th,
2014 at 9:00 to 12:00 PM and was located at the company's research object in Sengata, East Kutai, East Kalimantan. The elements of the company were present at the focus group session: BCRD Manager, Learning and Development Manager, PME Manager, and Manager of Community Empowerment. The government was reprenseted by Regional Development Bureau (BAPPEDA) and Public Works Department, while the other parties attended by representatives of Indonesian Youth National Committee KNPI and RKPL.

In FGD, experts were asked in advance to be able to explore and express their aspirations in a few questions related to Ten Issues and Trends in CSR in 2013 into a Form B which is used for completing the Development SAST.

1. Exploration of Strategic Assumptions SAST approach.

Assuming the initial exploration of strategic outlines the components of factors. Strategic assumption aspects factors are described in detail in Table 1.

2. Determination of Priority in Policy Development By using techniques SAST the the existing assumptions were rated. Graphically the rating is positioned in a Cartesian quadrant, so it I easy to see the position of importance and

Table 1. Strategic Assumption Factors

\begin{tabular}{llcc}
\hline No. & \multicolumn{1}{c}{$\begin{array}{c}\text { Strategic Assumptions Related with Human Resource } \\
\text { through Knowledge Transfer }\end{array}$} & Important & Certain \\
\hline A1 & Local License & 5 & 6 \\
\hline A2 & Integration of CSR to Main Business & 7 & 6 \\
\hline A3 & Collaborative Approach & 7 & 5 \\
\hline A4 & Human Rights Issues & 7 & 4 \\
\hline A5 & Local Content and Demand for Profit Sharing & 7 & 4 \\
\hline A6 & Supply Chain & 7 & 6 \\
\hline A7 & NGO Agendas & 6 & 4 \\
\hline A8 & Competition for Water Resources & 7 & 6 \\
\hline A9 & Employment Relations & 7 & 5 \\
\hline A10 & Transparency & 7 & 6 \\
\hline
\end{tabular}




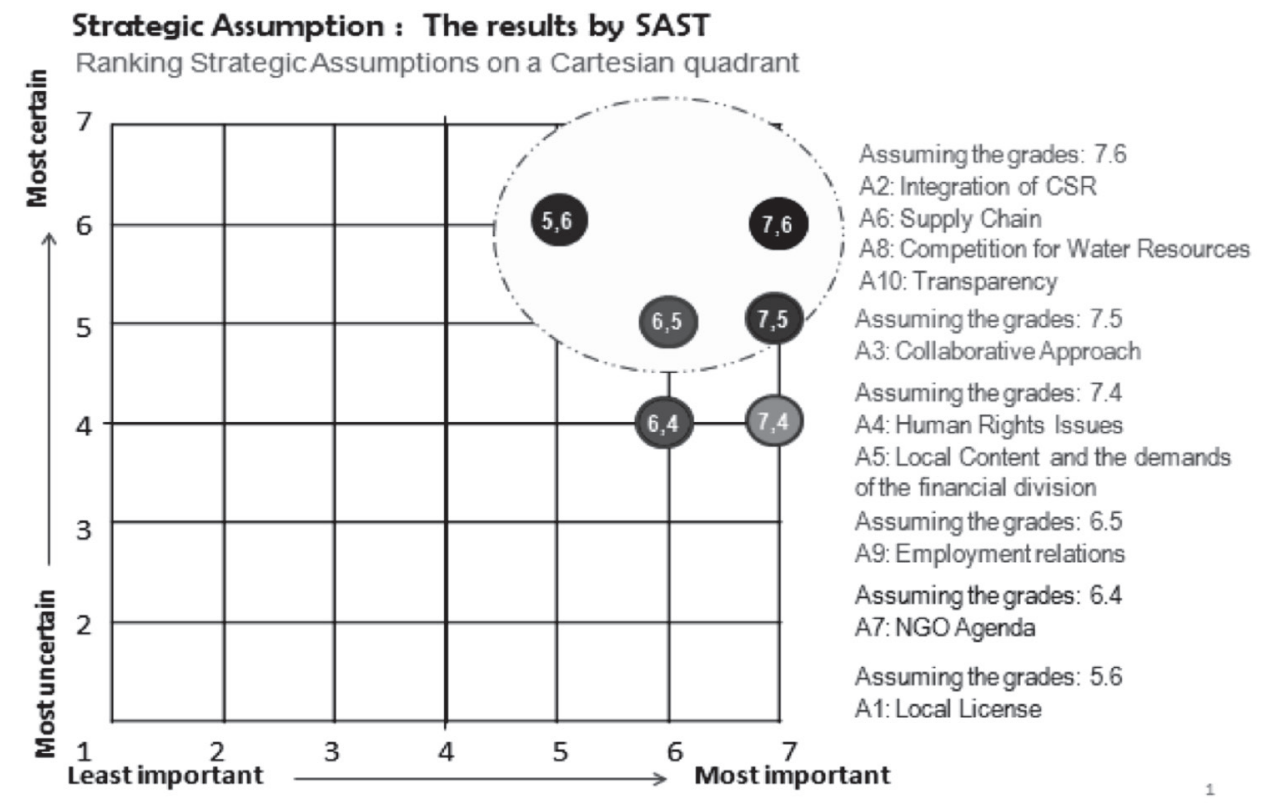

Figure1. Strategic Assumptions

certainty of any existing strategic assumptions. The Cartesian quadrant chart is presented in Figure 1.

The rating shows a picture of importance and certainty of available assumptions. For sharpening on things that must be considered in the process of policy drafting, the analysis and synthesis were carried out on the assumption in the first quadrant, position of which has the a relatively high degree of interest and certainty rate (Certain Planning Region). In Quadrant I can be identified assumptions as follows.

1. Assumptions with score 7.6 (absolutely important-very certain) are $\mathrm{A}_{2}, \mathrm{~A}_{6}, \mathrm{~A}_{8}$ and $\mathrm{A}_{10}$

2. Assumptions with score 7.5 (absolutely important-certain) is $\mathrm{A}_{3}$

3. Assumptions with score 7.4 (absolutely important-quite certain) are $\mathrm{A}_{4}$ and $\mathrm{A}_{5}$

4. Assumptions with score 6.5 (very importantcertain) is $A_{9}$

5. Assumptions with score 6.4 (very importantquite certain) is $A_{7}$

6. Assumptions with score 5.6 (penting-very certain) is $\mathrm{A}_{1}$
Strategic assumptions with an absolutly important value - very certain are $\mathrm{A}_{2}, \mathrm{~A}_{6}, \mathrm{~A}_{8}$ and $\mathrm{A}_{10}$. CSR integration, supply chain, competition and transparency of water resources are factors that are considered to be extremely important and very certain in affecting the clarity and accuracy of the strategic theme of CSR to increase organizational performance.

Strategic assumptions with an extremely important certain value is $\mathrm{A}_{3}$. Collaborative approach is a factor that is considered to be extremely important and certain in affecting the clarity and precision of the strategic theme of CSR to increase organizational performance. The collaborative approach is important for companies to consider partnering with local governments and the various elements of society. Some forms of cooperation that can be built are control of air quality and carbon emissions, climate adaptation, the use of water and land, and local employment.

Strategic assumptions with an extremely important-quite certain value are $\mathrm{A}_{4}$ and $\mathrm{A}_{5}$. Human Rights and Local Content and the demands of profit sharing are factors that are considered to be 
extremely important and quite certain in affecting the clarity and accuracy of the strategic theme of CSR to increase organizational performance.

The assumption of a very important strategiccertainly value is A9. The employment relationship is considered to be a very important factor and definitely affect the clarity and accuracy in strategic theme of CSR to increase organizational performance. Increasingly important for companies to revisit and improve labor management practices, the workers of contractors and business partners in order to avoid tensions and violent confrontations during ongoing business processes. Establishing cooperation with trade unions and local partners is an important issue for the company at this time.

Assumptions with very important strategic - quite certain value is $\mathrm{A}_{7}$. NGO agenda is a factor that is considered important and very certain in affecting the clarity and accuracy of the strategic theme of CSR to increase organizational performance. Companies need to reconsider their relationship with NGOs and seek constructive ways to find common ground in response to the latest issues, the transparency of management and various issues related to the responsibilities and human rights.

Strategic assumptions that are considered important and very certain is $A_{1}$. The existence of local community involvement in business strategy scheduled in the projects, community participation to build trust and partnerships with local communities is a factor that is considered important and very certain in affecting the clarity and accuracy of the strategic theme of CSR to increase organizational performance.

\section{Leadership Roles and Competencies}

In this session the entire primary data obtained by the FGD to thirteen experts who are representatives of companies, governments, educational institutions, youth organizations and
NGOs as well as the recording done during these discussions. The thirteen experts were actively involved in the discussion forum with duration of 1 to 3 hours. Focus group session was held on Thursday, August $29^{\text {th }}, 2014$ at 9:00 to $12: 00 \mathrm{pm}$ and is located at the company's research object in Sengata, East Kutai - East Kalimantan.

The elements of the company were present at the focus group session: BCRD Manager, Learning and Development Manager, PMEManager, and Manager of Community Empowerment. The government was reprenseted by Regional Development Bureau (BAPPEDA) and Public Works Department, while the other parties attended by representatives of National Committee of Indonesian Youth (KNPI) and RKPL.

In the focus group session, experts were asked in advance to be able to fill out, explore and express their aspirations in some of the questions related to the Roles and Leadership Competencies in order to improve the performance of CSR, especially in the field of company community development into a Form C. Form $\mathrm{C}$ is used to formulate the important roles and core competencies of leadership that directly relates with CSR performance.

Form $\mathrm{C}$ is divided into two parts, the first part is to reveal Role of Leadership in which eight (8) questions contained therein are based on empirical journal by Mohamad and Silong(2008), namely: Leading a multi-racial team, change agent, problem solver, negotiator or mediator, planning and conducting community programs, communicator, resource-linker and manager. The second part of Form $\mathrm{C}$ is used to reveal Leadership Competencies in which eight questions contained therein are based on empirical journal of Patricia and Tao (2011), namely: Networking/Collaboration across state lines, Understanding diversity/cultural differences, Relationship building, Understanding how leadership Affects community change, Communication, New outlook/clearer vision for the future, all working towards the same 
goal, the local state Understanding the roles and interactions in communities.

The result of the discussion on why the eight questions regarding the leadership role are considered important by the company and the brief reasons suggests an overview of the strategic assumption that the performance of CSR experts are strongly colored by the existing leadership roles within the organization. The results of focus group discussion (FGD) are as follows:

\section{Problem solver}

A leader must pay attention to all problems and solve them through a process of analysis and then follow up. Able to provide a reference to the team to coordinate and he needs to understand the root of the problem (root couse). Plays the role in the involvement of all components of society and provide positive and practical solutions as well as actively engaged in addressing all the problems. Contributes consultation or coordination with relevant agencies. Needs to understand the problems so that able to create maps of problemsolving strategies, to investigate the issues, data and related information that are important in the determination of programs and social engineering in solving problems. Able to conduct analysis of available data and information sources that can be an important part and also related to the views of other stakeholders in their own appropriate perspectives. Plays a proportional role not only in formal domains but also in partnering the problem. Does not only call in the law enforcement and then prepare a report, but expected to build relationship among communities, government and other stakeholders in order to achieve a common goal.

\section{Manager}

Plays the role in the social development of society and the business enterprise. Due to varied expectations of stakeholders he needs to be able to formulate priority of measures so that common goals can be achieved. Required to know the problems and conflicts in society and prepare the way and solutions to overcome them. Responsible for achieving and implementing appropriate work in accordance with the intended aims. Contributes to manage every aspect so that he should be the leader in the determination and direction of community development. Consistently oversee the process, outcomes, outputs, inputs, results in accordance with goal setting. Clear role and work direction in managing a wide range of issues and activities in the effort of achievement and community development.

\section{Resource-linker}

A leader contributes to synergize the implementation of the program and to improve the efficiency of each party involved in the achievement of a shared goal. Required to take active involvement so that people can and want to help him in providing solutions and cooperate with the government and other parties. Knows the needs of the community so that can be a mediator or filter the government in implementating the community programs. A communication liaison between the community, the individual with their leader and as a spokeperson for the community to speak to related parties and the government. Takes part in building a network or community of stakeholders across government, (NGOs) and other institutions and serves as a facilitator between the various stakeholders.

\section{Change agent}

A leader contributes to foster all programs reflecting the company's concern for the development of society. Drives changes towards a better condition relevant with the real issues. As a carrier of changes he must know the community basic need as accurate program implementation will resolve the main and principal problems. Becomes an agents of a larger change. Acts as a change benchmark and the originator of the idea and can internalize them into the society culture. Takes the role in mapping the problems and follows the trends. 


\section{Negotiator/Mediator}

Acts as a mediator or negotiator so that all problems can be mitigated and its larger impact on the community is minimized. Gives good model and is willing to take action in person and to observe actively all the problems. Delegates authority to subordinates so that together they can actively participate in addressing all the problems. As a mediator he is expected to help or give advice to make the way out of problems. As a mediator, has a special role that always must be attached in the context of conflict management. Acts as a behavior and system counterweight including the company's role in serving government programs in health, education and economic programs. Takes a role in connecting the key community figures into the approaching issues without being partial to any group.

\section{Planning and conducting community progams}

A leader must play a role in the planning and implementation of programs related to community development. The planning and implementation of community development programs must be integrated in order to create synchronization between the achievement of corporate objectives and interests of harmonious society. The planning and implementation should be comprehensive and inclusive of wide-ranging elements like the community, educational organizations, government and youth organizations.

\section{Communicator}

Able to communicate to all levels of society since it can build collaboration, solidarity and harmonious relationships that can generate a lot of brighter ideas for community development. Inappropriate communication will cause new problems and vice versa. Conveys improvement messages to the community, harmony of perspectives in solving problems. The quality of conveying the message becomes an important part in the process of multistakeholder communication especially related to the strategic issues that vulnerable of latent conflict in the communities. Takes part in communicating an idea or proposing a program and he is able to communicate both verbally and in writing. Has public speaking skills in communicating various issues, activities and community development programs either internally or publicly informing that the company has contributed and participated actively in community development effort.

\section{Leading a multi-racial community}

A community leader will help and continue to empower the community mutual help to strengthen their unity and unison. Partial attitude to certain group will lead to jealousy of others or potential inaccurate decisions. The leader is active in improving the unity and integrity of the community so as to avoid conflict and the community development goals can be achieved. Acts to unite various groups, each of which has a wide range of interests. Advances the community culture. He has no one-sided attitude, high nationalism and no interests of individual, groups, ethnic group and institutions. Takes an important part in maintaining sociologically the social stability. Primordial pattern based on ethnic, religion and race could create unfavorable condition. Some company programs appears to be biased towards the ethnic, religion and racial issues. Will actively make an effort that community members interrelate and know each other so as to build good cooperation and synergy in implementating the community development programs.

The result of the discussion on why the eight questions regarding the leadership competencies are considered important by the company and its brief reasons suggests an overview of the strategic assumption that the performance of CSR experts are strongly colored by the leadership competencies within the organization. The results of focus group discussion (FGD) are as follows:

\section{Networking/Collaboration across state lines}

A community leader is able to synergize programs relating to global, national issues that are also performed by other parties. Build a network among 
all parties that will accelerate the development and as a means of important information exchange that is expected in turn to create cooperation and exchange information for better stage. This is very important in relation to the quality and transparency between the company and local, national and international partners. This also important for companies to create a network up to $60 \%$ level of interest with local partners and up to $40 \%$ with national partners. This is very important for information exchange and as a channel for programs campaign and sharing of experience.

\section{Understanding diversity/cultural differences}

A community leader is able to appreciate and bring together diverse cultures. Able formulate and suitable strategy or the right decision in accordance with the actual conditions and situations. Able to maintain unity and union, understand local knowledge and preserve local culture. Gives respect to diversity and difference in perspectives and understands the specific situation that could result in a potential conflict.

\section{Relationship Building}

Takes a part in improving cooperation, quality of coordination, synergy among the parties in building a network. Establish wider cooperation and exchange of information. By maintain a good relationship and conducive with various parties he will bring in collective stamina in order to achieve a more quality development of community. Community synergy in implementing community development programs is very important because differences in perceptions and views with the community can be minimized and therefore new conflicts are prevented.

\section{Understanding how leadership affects community change}

A leader is very tolerant so that the impact of changes in the community would be excellent for the people and the companies. leading by example and will be trusted by the community. Organizes and implements all relevant programs in order to achieve common goals. Acts as a catalyst or indicator in viewing the changes in the community.

\section{Communication}

Built better and more appropriate communication, a balance between the public and companies is created. Able to deliver the programs and to invite people to join actively and to do more. Good communication is the good image and public trust for the company. Eminent communication skills can positively persuade to the relevant parties to take part in the development efforts and community empowerment.

\section{New outlook/clearer vision for the future}

A community leader has a vision of the future on creating success and balance in the community and the company. Able to respond properly to things that are predicted to take place by developing action plans at this time. Able not only to design but to implement, to evaluate the programs and to maintain and he has innovation for better stage. Visionary leader who is able to think into the future of sustainable development without damaging the past days. Can see the strategic thing and regional or local development agenda so that the community interests can be jointly accommodated in the future.

\section{All working towards the same goal}

This means there should be the same goals, vision and mission in order to make collective decision in achieving its objectives. A leader is able to achieve efficiency in human resources, funds, time and others in achieving a common goals. Able to find best solutions, committed to achieving the vision and realizing it and to focus on big goals shared between companies, governments and communities so as to create good synergy and collaboration. Able to take role as a catalyst for regional economic development.

Understanding local state roles and interactions in communities

Able to create harmony and balance the 
cooperation between the community and the company. Able to give the role and functions of each party appropriately so as to avoid overlapping. Able to stay on earth and to be concerned with local roles and to appreciate local wisdom.

In the focus group session the experts also expressed some collective concerns namely the development of the mining industry and of course the company prospect. Environment issues are now being seriously discussed by the community. Experts say that the current mindset of the people had been slightly shifted where before it was often stated all CSR activities are solely the responsibility of the company but nowadays due to awareness of all parties and intervention of local government, people say that the CSR responsibilities are a shared responsibility amongst companies, government and the communities. They are all responsible for maintaining the natural balance so that all can live side by side in harmony.

The opinion that the company has always been the actor in the environmental damage is no longer frightening to the community. This is because the community are also involved in the investigation of problems involving the company, the community and government. The experts also stated that the company has not yet taken powerful and intense communication and publication. This obviously refers to the roles and competencies of leadership in organizations especially the communication competence which is absolutely important for a leader in their role within the organization. Verbal and written communication become significantly important skills in CSR especially community development because all efforts can only be seen by the community using these skills.

Regarding community development and empowerment, the experts state that the companies have been very active, transparent and involved all relevant elements in formulating and implementing community development programs. A number of programs that have been administered to the community and deserve publication are: flood prevention and control, dengue fever disease prevention and control, the construction of roads and bridges, the provision of seeds, the provision of standard housing in deprived areas (self-reliant villages), participation in seminars or campaign against drugs abuse, provision of scholarships to communities, cleft lip surgery, placement of 100 local medical personnel to several hospitals as part of the effort to empower local communities to actively participate in the government efforts to compete for national award for cleanness and neatness by participating in the program against garbage. The company also provided aid and guidance to the community in waste management program. There are still a lot of other community development programs.

\section{MANAGERIAL IMPLICATIONS}

The results of FGD of experts, the strategic assumptions upon Top 10 CSR Issues and Trends gives an overview of important and certain priorities that should be done by the company on the most powerful and weakest strategic assumptions. Regarding the assumptions relating to strategic organizational leadership, the company has to improve or increase by organization intervention through Organisational Development (OD) in enhancing the role and competence of the organization's leadership. While regarding the most powerful strategic assumptions, the company has to maintain and improve the performance. Regarding the weakest strategic assumptions, the company needs to create special programs, improve, communicate and campaign CSR performance improvement programs, especially in the ares of local license ( $\left.\mathrm{A}_{1}\right)$, NGO Agenda $\left(A_{7}\right)$, labor relations $\left(A_{9}\right)$, Human Rights Issues $\left(A_{4}\right)$, Local Content $\left(A_{5}\right)$, and the collaborative approach and profit sharing $\left(\mathrm{A}_{3}\right)$ to all employees, and all division and the communities to minimize the negative perception that causes a conflict between the company and the government or community. There is a perception that activities related to CSR performance are not implemented 
consistently for not being communicated well and intensely.

\section{CONCLUSION}

FGD result and SAST process show that the $10 \mathrm{CSR}$ Issues and Trends from both strategic assumption and priority assumptions are reviewed by experts as very good and there are in quadrant I which sequence priority of strategic assumpution are local licence $\left(A_{2}\right)$, supply chain $\left(A_{6}\right)$, competition of water resources (A8) and transparency $\left(\mathrm{A}_{10}\right)$. But in some areas of strategic assumptions and policy priorities that still require serious attention are: CSR integration to the main business $\left(\mathrm{A}_{2}\right)$, NGO Agenda $\left(A_{7}\right)$, labor relations $\left(A_{9}\right)$, Human Rights Issues (A4), local content $\left(A_{5}\right)$, and the collaborative approach and profit sharing $\left(\mathrm{A}_{3}\right)$. FGD results state that the organizational leadership roles and competencies are very necessary and important or a leader in terms of CSR performance. The eight leadership roles are Leading multi-racial team, manager, mediator or negotiator, and resource-linker change agent, communication, problem solver, planning and conducting community programs. Eight leadership competencies are: Networking/ Collaboration across state lines, Understanding diversity/cultural differences, Relationship building, Understanding how Affects community leadership change, Communication, New outlook/ clearer vision for the future, all working towards the same goal, Understanding local state roles and interactions in communities.
While the mindset of the community have shifted. They are now aware that responsibility CSR is a shared responsibility among the companies, the government and the communities and thy are responsible to constantly maintain the natural balance so that all can live side by side in harmony. The experts also stated that the company has not yet taken powerful and intense communication and publication. This obviously refers to the roles and competencies of leadership in organizations especially the communication competence which is absolutely important for a leader in their role within the organization. Verbal and written communication become significantly important skills in CSR, especially community development because all efforts can only be seen by the community using these skills. The experts also state that the companies have been very active, transparent and involved all relevant elements in formulating and implementing community development programs.

\section{Future Research}

Research carried out in the mining companies listed in the Indonesia LQ45 can be developed further for future research involving companies of other sector listed in LQ45 as research objects. Otherwise, this can be used to conduct similar study toward similar companies located in the vicinity of the company being researched.

\section{REFERENCES}

Avolio, B.J., \& Bass, B.M. (1995). Individual consideration viewed at multiple levels of analysis: A multi-level framework for examining the diffusion of transformational leadership. Leadership Quarterly, 6(2), 199-218.

Bass, B.M. (1985). Leadership and performance beyond expectations. New York: Free Press.

Bass, B.M. (1990). Bass and Stodgill's handbook of leadership: Theory, research, and managerial applications (3rd ed.). New York: Free Press.

Bass B M. dan Avolio B J. 1993. Transformational leadership: A Response to Critiques. In M. M. Chemers \& R. Ayman (Eds.), Leadershiptheory and research: Perspectives and directions (pp. 49-80). San Diego, CA: Academic Press.

Bass, B. M. (1997). The Ethics of Transformational Leadership. KLSP: Transformational Leadership, Working Papers, Academy of Leadership Press. 
Behling, O., \& McFillen, J.M. (1996). A syncretial model of charismatic/transformational leadership. Group \& Organization Management, 21(2), 163-191.

Bird, R., A. Hall, F. Momente and F. Reggiani (2007), “What Corporate Responsibility Activities Are Valued By the Market?", Journal of Business Ethics, 76, 2, pp. 189 - 206.

Branco, M. C. and Rodrigues, L. L (2006). "Corporate Social Responsibility and Resource-Based Perspectives", Journal of Business Ethics, vol. 69, pp. 111-132.

Carroll, A.B., and A.K. Buchholtz. (2003). Business and Society: Ethics and Stakeholder Management. 5th ed. Australia: Thomson South-Western.

D'Amato, Alessia, S. Henderson, and S. Florence (2009). Corporate Social Responsibility and Sustainable Development: A Guide to Leadership Tasks and Functions. Greensboro, NC: Center for Creative Leadership.

Davis, J. P, \& Oxman, M., 2013. BSR Insight Articles. Top 10 CSR Issues and Trends for The Extractives Industry in 2013. The International Resource Journal. Publication date January 15, 2013. www.bsr.com.

Finkelstein, S. and D.C. Hambrick. (1996). Strategic leadership: Top executives and their effects on organizations. New York: West Publishing Company.

Fiori, G., F. Donato and Izzo, M. F. (2007). "Corporate Social Responsibility and Firms Performance. An Analysis on Italian Listed Companies", working papers, LUISS Guido Carli University, Rome: Italy. Available From http://ssrn.com/ abstract $=1032851$.

Fiedler, F.E. (1967). A theory of leadership effectiveness. New York: McGraw-Hill.

Goleman D, Boyatzis, R, Mekee A. (Alih bahasa Susi Purwoko) 2004. Primal Leadership (Kepemimpinan Berdasarkan Kecerdasan Emosi). Jakarta: PT Gramedia Pustaka Umum

Handelman JM, R Bello. 2004. "Community Oriented Corporate Social Responsibility: Consumer Evaluation of Community Attachment”, Advances in Consumer Research, Vol. 31.

Hater, J., \& Bass, B.M. (1988). Superiors' evaluations and subordinates' perceptions of transformational and transactional leadership. Journal of Applied Psychology, 73(4), 695-702.

Hope, K. R. Social Change and Rural Regional Community Development in the United States. Community Development Journal, 1980, 15 (2), 110-116.

Ivancevich J M., Konopaske R M. dan Michael T. 2011. Organizational Behavior and Management. Nineth Edition. New York: McGraw Hill. International Edition.

Johnsen T, and O. Gjoelberg (2009). "Management of The Norwegian Oil Fund: The Challenges and Costs of Being Ethical". Scandinavian Journal of Business Research 23 (2), pp. 1-26.

Liu, H. and M. Fong (2010). "The Corporate Social Responsibility Orientation of Chinese Small and Medium Enterprises", Journal of Business Systems, Governance and Ethics, Vol. 5, No. 3, pp. 33-50.

Locander W, Hamilton F, Ladik D, Stuart J. 2002. Developing a leader rich culture: The missing link to creating a marketfocused organization. Journal of Market Focused Management, 5(2), 149-163 (June 2002).

Lok P. dan Crawford J. 2001. The effect of organizational culture and leadership style on job satisfaction and organisationl commitment - A cross-national comparison. Emerald Insight

Lyon, T. P., and J. W. Maxwell (2008). "Corporate Social Responsibility and the Environment: A Theoretical Perspective", Review of Environmental Economics and Policy, Vol. 1, Issue 0, pp. 1-22, Oxford University Press.

Mohamad, M., and Silong, A.D., (2008), Leadership Roles in Community Development in Malaysia.Ministry of Science, Technology and Innovation Abu Daud Silong, Faculty of Educational Studies, Universiti Putra Malaysia.

Margolis, J. and H. Elfenbein (2007). "Do Well by Doing Good? Don't Count On it”, Harvard Business Review, Social Responsibility, Special Issue on HBS Centennial, 86 (1), 19.

Patricia, Clark, and Tao Gong (2011). Developing leadership competencies to promote the community the Missisipi Delta Region. SSN: 1712-8277 (c) Journal of Rural and Community Development. www.jrcd.ca

Neal, A. C. (2008). “Corporate Social Responsibility: Governance Gain or Laissez-Faire Figleaf?”, Comparative Labour Law \& Policy Journal, Vol. 29, pp. 459-474.

Pearce, J.A., and R. B. Robinson (2011). Strategic Management: Formulation, Implementation and Control, 13th Ed. McGrawHill, New York: USA.

Ploch, L. A. Community Development in Action. Journal of Community Development Society, 1976, 7 (1), 1-10.

Sanders, I. T. Theories of Community Development, Rural Sociology, 1958, 23 (1), 1-12.

Spada, 2008. Environmental Reporting - Trends in FTSE 100 Sustainability Reports. Spada, London: UK.

Swanson, Diane L. 1995. Addressing a Theoretical Problem by Reorienting the Corporate Social Performance Model. Academy of Management Review, 20 (1): 43-64.

Uwuige, Uwalomwa, Olubukunola Uwigbe, and Ben Caleb, 2011. Corporate Social Responsibility Disclosures by Environmentally Visible Corporations: A Study of Selected Firm in Negeria. European Journal of Business and Management. Vol 4, No. 5. 
World Business Council for Sustainable Development 2000. "Corporate Social Responsibility", World Business Council for Sustainable Development http://www.wbcsd.org/home.aspx.

Yammarino, F., \& Bass, B.M. (1990). Transformational leadership and multiple levels of leadership. Human Relations, 43, 975-995.

Yukl, G.A. (1989). Leadership in organizations (2nd ed.). Englewood Cliffs, NJ: Prentice-Hall.

Zaleznik, A. (1963). The human dilemmas of leadership. Harvard Business Review, 41(4), 49-55 